\title{
Birmingham Medical Research Expeditionary Society 1977 Expedition: Psychological aspects of acute mountain sickness
}

\author{
*J. EdWARd Olive \\ M.B., Ch.B., M.R.C.Psych. \\ $\uparrow N$. WATERHOUSE \\ M.B., Ch.B.

\begin{abstract}
*All Saints Hospital, and $† Q u e e n$ Elizabeth Hospital, Birmingham B18 5SD
\end{abstract}
\begin{abstract}
Summary
In order to assess the importance of personality and expectations in the development of Acute Mountain Sickness (AMS), 3 standard personality questionnaires and a Mountain Sickness Anticipation Questionnaire were completed by all of the 17 BMRES expedition members before their departure for the Himalayas. AMS could not be predicted with these tests and its occurrence, when assessed either by clinical interview or by peer review, bore no significant relationship to personality. For comparison daily self-assessment of the signs and symptoms of AMS were also conducted throughout the expedition, using graduated and graphic rating scales. The results were found to be unreliable and dependent upon personality factors. These findings have implications for those assessing others at high altitude.
\end{abstract}

\section{Introduction}

Most symptoms of acute mountain sickness (AMS) are referable to the central nervous system, which led Slater and Roth (1969) to describe the principal symptoms of AMS as psychological. These are generally indistinguishable from the normal responses to mental or physical stress, which, in turn, are variably dependent on many factors such as motivation, expectation and personality. It is to these factors that Heath and Williams (1977) referred when they concluded that psychological aspects undoubtedly existed in the development of and response to AMS. Opinion varies as to who is most likely to develop AMS. For example, while some believe agressive mountaineers are more often victims of AMS, Singh (1964) declared that individuals of a nervous temperament and psychological instability are not likely to do well at great elevations. Heath (Heath and Williams, 1977) on the other hand, believed that it was not possible to predict the behaviour of sea-level subjects at high altitude.

The subjective nature of psychological symptoms makes them extremely difficult to measure. Evans (1966) devised a graduated rating scale which he called the General High Altitude Questionnaire.
He showed it to be a reliable means of quantifying the severity of subjective symptomatology but he only used it in simulated high altitude conditions. As an alternative graphic rating scales can be used. These scales, which are extensively used in psychological assessment, are particularly suitable for subjective symptoms, such as anger, that exist in a continuum. The purposes of the study were fourfold:

(1) To investigate the relationship between personality and the development of AMS.

(2) To determine whether AMS could be predicted.

(3) To examine (a) whether tough attitudes altered the incidence of AMS and (b) whether its presentation was altered by the expectation of particular symptoms.

(4) To ascertain whether there were advantages in using a graphic, as opposed to graduated, rating scale for self-assessment of subjective symptomatology of AMS.

\section{Methods}

Before departure, members completed 3 standard personality questionnaires, namely, the Sixteen Personality Factor Questionnaire (16PF); the Eysenk Personality Questionnaire (EPQ); the Hostility and Direction of Hostility Questionnaire (HDHQ); and a fourth, the Mountain Sickness Anticipation Questionnaire (MSAQ) constructed for this study. This last comprised of 5 parts:

(1) Five point scale for rating the likelihood of the subject himself suffering from AMS.

(2) Anticipated toughness in combating AMS.

(3) Eight common symptoms of AMS (anorexia, breathlessness on normal activity, chest discomfort, dizziness, cough, headache, nausea and thirst), to be rank ordered from most to least likely to be suffered at high altitude.

(4) Five point scales for rating the likelihood of becoming more critical, indifferent, impatient, irritable, angry or miserable at high altitudes.

(5) To select the 3 members most likely to succumb to AMS. The questionnaires were examined on return from the expedition.

Graduated (Table 1) and graphic rating scales 
TABLE 1. Graduated rating scale

\begin{tabular}{lll}
\hline & Absent Mild Moderate & Severe \\
\hline Headache & & \\
Dizziness & & \\
Anorexia & & \\
Nausea & & \\
Vomiting & & \\
Diarrhoea & & \\
Thirst & & \\
Breathless on normal & \\
activity & \\
Cheyne-Stokes & \\
Cough & \\
Chest discomfort & \\
\hline
\end{tabular}

(Table 2) were filled-in daily at midday, during the expedition, and in most cases for at least a fortnight before departure. The methods of obtaining clinical interview and peer review assessments of AMS are
AMS. Anticipated toughness and the expectation of AMS were compared with the actual occurrence as assessed by clinical interview. The expected symptoms of the group as a whole were determined by summating and ranking the individually ranked 8 common symptoms from the MSAQ. These were then correlated with the ranked sum of those occurring above and below $3000 \mathrm{~m}$ for 7 consecutive days (Table 3). Individual symptom expectations were compared with self-rated outcome. Self-rated symptoms were correlated with clinically assessed AMS and altitude.

The ranked variables were compared using Spearman's rank correlation technique, and the significance of the correlation coefficients were determined by reference to standard statistical tables.

TABLE 2. Graphic rating scale

\begin{aligned} & \hline On waking: tired $\longleftarrow 6 \mathrm{~cm} \longrightarrow$ Refreshed \\ & Sleep: interrupted Uninterrupted \\ & Sleep: less than usual More \\ & Normal activity: effort Effortless \\ & Miserable Cheerful \\ & Angry Placid \\ & Fatigued Energetic \\ & Irritable Calm \\ & Concentration: poor Good \\ & Memory: poor Good \\ & Impatient Patient \\ & Indifferent Keen \\ & Critical of others Uncritical \\ & \hline\end{aligned}

described by Fletcher (1979). Self-assessment ratings were derived by rank ordering the sum of an individual's signs and symptoms experienced over $3000 \mathrm{~m}$ as recorded on the graduated rating scale. The rank ordered measurements of all the personality factors were correlated with the 3 assessments of AMS and also the rank order of those members thought by others to be most likely to suffer from

TABle 3. Sum of symptom scores for 7 consecutive days. mild: 1 ; moderate: 2 ; severe: 3

\begin{tabular}{lcccc}
\hline & $>3000 \mathrm{~m}$ & (rank) & $<3000 \mathrm{~m}$ & (rank) \\
\hline Headache & 80 & 1 & 24 & 3 \\
Breathlessness on & & & & \\
normal activity & 79 & 2 & 9 & 6 \\
Cheyne-Stokes & 56 & 3 & 4 & 7 \\
Cough & 33 & 4 & 4 & 8 \\
Thirst & 32 & 5 & 46 & 1 \\
Anorexia & 27 & 6 & 17 & 4 \\
Diarrhoea & 26 & 7 & 35 & 2 \\
Dizziness & 22 & 8 & 2 & 9 \\
Nausea & 12 & 9 & 15 & 5 \\
Chest discomfort & 7 & 10 & 1 & 11 \\
Vomiting & 5 & 11 & 4 & 10 \\
\hline
\end{tabular}

\section{Results}

The EPQ demonstrated a bias towards the stable and extroverted. In spite of being a heterogeneous group of personalities, only 2 of the 16PF factors in both forms A and B departed from the norm, intelligence and Factor M. The latter indicated, for example, that the group was less conventional and more creative than normal.

The self-rating assessment correlated with neuroticism (EPQ $P<0.05$, insecurity $(16 \mathrm{PF} /$ factor $\mathrm{O}$ ) $P<0.05$, and internally directed hostility (HDHQ) $P<0.02$. However, there was no significant correlation between personality and mountain sickness when the latter was judged by clinical interview or peer review.

There was a significant correlation between the 4 members judged by the group most likely to suffer from AMS and externally directed hostility (HDHQ) - a clear case of wish fulfilment.

Individuals could neither predict the likelihood of their developing AMS nor could they predict it in others. Anticipated fortitude in coping with symptoms bore no significant relationship to AMS. The 
rank ordering of 8 common symptoms in the MSAQ correlated closely with those experienced above $3000 \mathrm{~m}$ and poorly with those below.

The results obtained from the graphic rating scale are shown in Table 4; only the symptoms that symptoms and their development. The fact that tough attitudes did not alter the incidence of AMS suggests that the belief of a relationship between them could best be explained by an association with tendencies to trek high, too fast.

TABLE 4. Significant correlation with altitude

\begin{tabular}{|c|c|c|}
\hline & AMS group & Non-AMS group \\
\hline Fatigue & Significant at $0.1 \%$ & No significant correlation \\
\hline Indifference & , $\quad 0.5 \%$ & 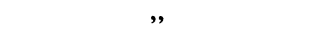 \\
\hline Poor memory & $0.5 \%$ & , \\
\hline Poor concentration & $2.0 \%$ & ,, \\
\hline Misery (depression) & $2 \cdot 0 \%$ & ,, \\
\hline Tired on waking & $\Rightarrow, \quad 5.0 \%$ & ,, \\
\hline Normal activity an effort & No significant correlation & Significant at $5 \%$ \\
\hline
\end{tabular}

correlated significantly with increasing altitude are included. The 'AMS group' refers to those 5 members who definitely suffered the condition (Fletcher, 1979). The graphic rating scale revealed no subtle insights into early psychological changes that might be associated with AMS and there were blatant inaccuracies in the self-scoring. For instance, a member who was manifestly exhausted rated himself as 'not unusually fatigued'.

\section{Discussion}

The graphic rating scale was laborious to interpret and of no particular advantage over the graduated scale, even in the hands of several who had experience of the former in their previous research work. Examination of Table 4 may apparently support its usefulness in elucidating the psychological symptoms of AMS. However, the fact that there was no significant correlation between the AMS group and normal activity above $3000 \mathrm{~m}$ being an effort, which it obviously was, indicates the unreliability of this method and seriously questions the value of the results, particularly in making judgements on individual symptoms. Nonetheless, Fletcher (1979) showed that overall the self-assessments derived from the graduated scale correlated highly with the other 2 methods.

If the personality questionnaires particularly the 16PF, had been examined before the outset, certain simple interpretations might have helped the leader to anticipate and foil potential problems.

That the symptoms over $3000 \mathrm{~m}$ were accurately anticipated can be put down to educated guessing. However, close examination of idiosyncratic predictions is highly suggestive of there being no important relationship between the expectation of
The unpredictability of AMS is confirmed and it is clear that personality is of no significance in the development of AMS but was important in influencing self-rating of symptom severity. Thus it is apparent that paradoxically those least likely to reveal to others, and probably to themselves, the severity of their symptomatology are not the neurotic and insecure but self-confident and stable individuals. It is with these people, whose opinions are most likely to be accepted at face value and who are able to criticize and act out hostility, that contradiction ando control will be most difficult. Quite simply, the neurotic and self-critical will be all too aware of their problems and readily and easily reveal them? By way of contrast, the stable and self-assured person who does not take kindly to interference, or has reason to doubt his own ability, may be the one most likely to delude himself and others as to his fitness to proceed. Leaders and responsible group members must be prepared to be thought wrong and make unpopular decisions, if they are to ensure the safety of their teams.

\section{References}

Evans, W.O. (1966) Measurement of subjective symptomatology of acute high altitude sickness. Psychological Reports, 19, 815.

FletChER, R.F. (1979) Birmingham Medical Research Expeditionary Society 1977 Expedition: Signs and symptoms. Postgraduate Medical Journal, 55, 461.

Heath, D. \& Williams, D.R. (1977) Man at High Altitude, pp. 117-118, Churchill Livingstone, Edinburgh.

SINGH, I. (1964) Medical problems during acclimatization to high altitude. In: The Physiological Effects of High Altitude (Ed. by Weihe, W.H.) p. 333. Pergamon Press, Oxford.

Slater, E. \& Roth, M. (1969) Clinical Psychiatry, 3rd edn, p. 439. Baillière, Tindal \& Cassell, London, New York. 